\title{
Relationship Between Diversity Management With Organizational Growth of Erzurum Physical Education Teachers
}

\author{
Gul Eda Burmaoglu \\ Correspondence: Gul Eda Burmaoglu, Faculty of Sport Sciences, Ataturk University, Erzurum, Turkey.
}

Received: July 18, 2018

doi:10.11114/jets.v6i9a.3497
Online Published: July 31, 2018

URL: https://doi.org/10.11114/jets.v6i9a.3497

\begin{abstract}
The main goal of this study is to investigate relationship between diversity management and organizational development of the physical education teachers of Erzurum. This research is a descriptive - correlation study. 55 physical education teachers of Erzurum participated in this research. Villamil diversity management (2007) and organizational development Power questionnaire (2008) have been used as a research tool. Cronbach's alpha was used to test the confidence to manage the diversity of 0.76 and 0.84 respectively for organizational development which reflects the reliability of research. Pearson and Variance analysis were used to get results. The results of study showed a significant correlation between diversity management and organizational development. As well as the dimensions of diversity management and organizational development.
\end{abstract}

Keywords: diversity management, organizational development, physical education teachers

\section{Introduction}

The diversity management with using all capacities and touches try to maximize and optimize the individuals' ability for making the highest efficacy (Gullu, 2010). Researchers have stated the concept of the diversity through many various methods and approaches. Emiko and Eunmi (2009) have categorized the concept of the diversity as the relationship with the job such as the job experiences and skill but the same diversity is little related to the demographical differences such as gender, race and age. Some other recent differences in the gender, race and age diversity have been categorized into the appearance level and differences in values, attitudes and personality diversity as the deepest level (Serhat et al, 2015). On the other hand, researchers have stated in their studies that according to the physical education teachers' viewpoint, other educational teachers' attitudes do not have any attitudes towards the lesson of the physical education and they little notice to the related lesson (Firat et al, 2013). The growth is subjected to the meaning of the planned optimization of a person or the collection of individuals in order to implement the highest potential missions and organizational purposes (Gerol et al, 2011). The graduators of the physical education field can use the abilities and skills of the educational term in order to optimize the social health and the country's sport progression (Firat et al, 2013). In the new concept of the growth regarding to the humanistic resources, the organizational human beings should be equipped with the sciences that these should not be made of some problems and all these sciences must have be implemented in the implementation of the organizational missions. In small organizations due to the scarce humanistic resources, the proportion of losing a person is very sensitive case and indeed these are seeking to the path where it has to solve all related problems regarding to the organizational commitment and employment. Of course the related problems due to the scarce of the skillful staffs and the tendency of the related staffs to change their occupations should be paid attention and for the reason, the growth of the humanistic growth is a facilitator for the staffs' learning process and the diversity is mainly felt in this pavement and one of the most important aspects of the related process is subjected to the staffs' commitment towards the same organization; as a consequence, the educational organization can make importance of the growth issues regarding to its own organization because this will keep its humanistic resources successfully. The struggles of the organizational growth are firstly paid attention to groups. The fundamental assumption is that when stepping towards the health and organizational effectiveness, the groups are subjected to those basic units that they should be potentially changed. The personal learning and changes should be also allocated into the organizational growth programs and these programs should not only be implemented in the minor issues; the organizational growth struggles are originally established based on reactive cases. All the interventions and struggles being participated in the organization should point to the fact that all struggles and activities should be oriented in the direction of changes optimistically. Hence, the organizational growth struggles are very different than other educational 
strives such as the educational courses or the management educational job-groups that have been designed for optimizing and increasing the knowledge, skill and perception of the participants. In teachers of other groups the purpose is that the students should learn something that this has to be applied in other opportunities while the organizational growth struggles of physical education teachers design the activities that these have reactive origin being immediately implemented in bonding to the organizational growth struggles. In the educational programs of teachers of other groups the process of learning is made of the framework that the transformation of the knowledge into the real context of the same organization cannot be confided in this pavement while the organizational growth struggles of the physical education teachers have active organizational members for implementing all active learning programs that the lack of this kind of imperative case can make some side-effects such as the lack of applying the skills and talents of the physical education teachers regarding to optimize the superior purposes of the organization and the lack of having a vital role for the behavior evolution, attitudes and skills, the lack of arrangement and planning, the lack of physical education lesson effectiveness and the lack of commitment of teachers towards the organizational purposes and this finally will lead to the reduction of the physical education teachers' dynamic activity making these teachers to get out of the life freshness; this will make them to get out of reaching to the superior organizational purposes. The diversity management is one of the most effective factors of the organizational growth. The related diversity management using the job force based on the divers' demography can optimize and boost the recent talents; the inter-group diversity is making the positive consequences when it will be managed as an effective case (Stefan Robbins, 1998, cited of Serhat et al, 2014). According to the above-mentioned cases, the present study is to respond to the question whether there is a relationship between the diversity management with organizational growth of Erzurum City physical education teachers? Atali (2009) showed that there is a positive relationship between the office of the job force and the process of the knowledge-making in the higher education system; the effectiveness management can bring a kind of knowledge-making into the organization. Gullu (2010) concluded that there is a positive significant relationship between the diversity management and the efficacy of the human force as well as its dimensions. Goral (2011) concluded that the degree of the social participation of the racial minority students is little than the Persian students and the degree of the social participation of the religious minority students is little than the Shiite Muslim students. The mean social participation of students is established based on the degree of applying the diversity management skills of the religious issues and based on applying the diversity management skills regarding to the racial issues of managers, there is observed a significant difference in this pavement. A competence between managers having MA and PhD certificates can be observed a kind of difference between the related populations. Also, there is no observed a significant difference between the educational certificate and the inconvenient beliefs. On the other hand, the mean social participation of students based on the degree of applying the skills of the religious diversity management and the degree of applying the racial diversity management skills showed a significant difference; hence, the factor of applying the cultural diversity management skills (regarding to the racial and religion diversities) can be considered as the greatest factor for increasing the social participation level of students effectively. Allen et al (2008) showed that the staffs' perception from the diversity of the top management level and non-managerial level with organizational performance have positive relationship together. Gullu (2014) concluded that there is a significant relationship between the diversity management and organizational commitment. In this study, the organizational commitment is considered as the criteria variable and the diversity management, gender, education, age and race are considered as the predicting variables getting entered into the regression model. The results showed that among the variables the management of diversity, the religion and gender are the predicting variables for the staffs' organizational commitment.

\section{Methods}

This study is carried out based on descriptive-correlation type of study as cross-sectional case. The research statistical population: the statistical population of the study includes all physical education teachers of Erzurum City and the number of the population is about 112 people. The statistical sample and sampling method: due to the restriction, the number of the population volume is equal with the sample volume.

\subsection{Measuring Tool}

Two standard questionnaires are applied in order to measure the related study:

Diversity management questionnaire: This questionnaire is designed by Williamil (2007) that has been given in the article of the investigation of the relationship between the diversity management and the organizational attraction. This questionnaire has been represented in eight elements of using the advantage of applying the diversity, positive share of diversity in organizational progression, lack of discrimination, respect, construction of the cultural policies for valuing for getting better results, the suitable proportion of the diversity and the design of the policy for removing the discrimination that every element has got 5 questions including 40 questions totally.

Organizational growth questionnaire: This questionnaire has been led by Power (2008) in an article titling the 
representation of a pattern for the growth of the scientific board members with the fundamental data theory approach having four elements as following: personal, professional and educational dimensions.

Validity of measuring tool: Cronbach alpha method is applied in order to determine the validity of the test using SPSS20. Cronbach alpha coefficient for the diversity management questionnaire is obtained 0.76 and this also is obtained for the organizational growth questionnaire as 0.84 in this study.

\subsection{Data Gathering Method}

The preliminary data is applied in order to gather the related data.

\subsection{Statistical Methods}

Pearson correlation coefficient, t-independent test and variance analysis test are also applied in this study as the

\section{Results}

Table 1. Correlation coefficient between the diversity management and organizational growth

\begin{tabular}{|c|c|c|c|c|}
\hline Independent variable & Dependent variable & $\mathrm{N}$ & Correlation & Sig. \\
\hline \multirow[t]{4}{*}{ Diversity management } & Organizational growth & 55 & $0.854 * *$ & 0.000 \\
\hline & Personal dimension & 55 & $0.836^{* * *}$ & 0.000 \\
\hline & Professional dimension & 55 & $0.822 * *$ & 0.000 \\
\hline & Educational dimension & 55 & $0.825 * *$ & 0.000 \\
\hline \multirow{4}{*}{$\begin{array}{l}\text { The application of the advantage of applying the } \\
\text { diversity }\end{array}$} & Organizational growth & 55 & $0.712 * *$ & 0.000 \\
\hline & Personal dimension & 55 & $0.707 * *$ & 0.000 \\
\hline & Professional dimension & 55 & $0.610 * *$ & 0.000 \\
\hline & Educational dimension & 55 & $0.635 * *$ & 0.000 \\
\hline \multirow[t]{4}{*}{ Positive share in organizational progression } & Organizational growth & 55 & $0.786 * *$ & 0.000 \\
\hline & Personal dimension & 55 & $0.876 * *$ & 0.000 \\
\hline & Professional dimension & 55 & $0.611 * *$ & 0.000 \\
\hline & Educational dimension & 55 & $0.709 * *$ & 0.000 \\
\hline \multirow[t]{4}{*}{ Lack of discrimination } & Organizational growth & 55 & $0.945 * *$ & 0.000 \\
\hline & Personal dimension & 55 & $0.875^{* *}$ & 0.000 \\
\hline & Professional dimension & 55 & $0.865 * *$ & 0.000 \\
\hline & Educational dimension & 55 & $0.912 * *$ & 0.000 \\
\hline \multirow[t]{4}{*}{ respect } & Organizational growth & 55 & $0.834 * *$ & 0.000 \\
\hline & Personal dimension & 55 & $0.6543 * *$ & 0.000 \\
\hline & Professional dimension & 55 & $0.912 * *$ & 0.000 \\
\hline & Educational dimension & 55 & $0.801 * *$ & 0.000 \\
\hline \multirow[t]{4}{*}{ The construction of cultural policies for valuing } & Organizational growth & 55 & $0.765 * *$ & 0.000 \\
\hline & Personal dimension & 55 & $0.653 * *$ & 0.000 \\
\hline & Professional dimension & 55 & $0.712 * *$ & 0.000 \\
\hline & Educational dimension & 55 & $0.795 * *$ & 0.000 \\
\hline \multirow[t]{4}{*}{ Valuing for obtaining better results } & Organizational growth & 55 & $0.710 * *$ & 0.000 \\
\hline & Personal dimension & 55 & $0.755^{* *}$ & 0.000 \\
\hline & Professional dimension & 55 & $0.602 * *$ & 0.000 \\
\hline & Educational dimension & 55 & $0.725 * *$ & 0.000 \\
\hline \multirow[t]{4}{*}{ Proportion of suitable diversity } & Organizational growth & 55 & $0.629 * *$ & 0.000 \\
\hline & Personal dimension & 55 & $0.511 * *$ & 0.000 \\
\hline & Professional dimension & 55 & $0.612 * *$ & 0.000 \\
\hline & Educational dimension & 55 & $0.602 * *$ & 0.000 \\
\hline \multirow[t]{4}{*}{ Designing the policy for removing discrimination } & Organizational growth & 55 & $0.723 * *$ & 0.000 \\
\hline & Personal dimension & 55 & $0.712 * *$ & 0.000 \\
\hline & Professional dimension & 55 & $0.622 * *$ & 0.000 \\
\hline & Educational dimension & 55 & $0.712 * *$ & 0.000 \\
\hline
\end{tabular}

According to table 1, it is specified that there is a positive significant relationship between the diversity management and the advantage of application of the diversity management advantage and the positive share of the diversity in organizational progression and the lack of discrimination and the construction of the cultural policies and valuing to obtain the better results for valuing and the suitable proportion of the diversity and design policies for removing all discriminations with organizational growth.

\section{Discussion and Conclusion}

The results represent that there is a positive significant relationship between the diversity management with the organizational growth (personal, professional and educational dimensions) of physical education teachers of Erzurum City that these are adapted with the results of Firat et al (2013) that they have also reported a significant relationship between 
the diversity management and the organizational growth of the physical education scientific board members in all over the country. Based on the results of the diversity management studies, there is established a positive effect on the person, group and the organizational consequences (Doherty and Fink, 2010), the relationship with praise, optimization and leadership (Emiko and Eunmi, 2009), increase of staffs' temperament and success (Stefan and Collins, 2008), the effectiveness on the organizational behavior and strategy (Forest and Rioz, 2008), recovery of top management team (Seed and Moore, 2008), the recovery of the organizational performance (Hess and Lovler, 2008; Allen et al, 2008), increase of efficacy, organizational commitment (Gullu, 2010), knowledge-making in an organization (Atali, 2009). By considering the results based on the positive effects of the diversity management with high number of the organizational behavior elements, the existence of the relationship between the diversity management and organizational growth are adapted together. When every program or a new style is getting successfully achieved, all staffs will be basically participated making a kind of feeling that all of these staffs are really effective in organizational planning affairs. In this study, there is a positive significant relationship between the diversity management and organizational growth with positive correlation coefficient in $99 \%$ sig level; in other words, according to the physical education viewpoint by applying the diversity management the organizational growth will be increased, too. That is, when the diversity management is recovered, these indexes will be naturally increased. It seems that when the related teachers are benefitted from the highest diversity management, they will help on the schools' organizational growth more and more. Indeed, the increase of the diversity among the schools will lead to the growth particularly the increase of the diversity management along with the physical education teachers will make a dynamic and happy environment for the school atmosphere. The results represent that there is a positive significant relationship between the applications of the diversity management advantage with the organizational growth of Erzurum City physical education teachers. The results of the study are adapted with the results of Parker (2002) that he has also reported the significant effect of using the diversity management in the organizational growth. In other words, it can be claimed that one of the most sophisticated advantages of the diversity management is subjected to the increase of the organizational growth. Due to the mentioned issues by increasing the advantage of the diversity application, the organizational growth will be also increased, too. The results represent that there is a positive significant relationship between the positive share of the diversity and the organizational growth in Erzurum City physical education teachers significantly. The results of the related section are adapted with the results of Serhat et al (2015) that they reported a positive significant relationship between the diversity share and the organizational growth of the scientific board members of the university in all over the country.

The results showed that there is a positive significant relationship between the lack of discrimination with the organizational growth of Erzurum City physical education. Many individuals accept consciously that they tend to get little money but they want to work in a location where they tend to be conducted by their own orientation feeling little discrimination and they try to have better organizational justice and growth. Indeed, the positive discrimination is considered as a structured and targeted intervention in management representing the chance of the lack of balance amendment, injustices, mistakes or apparent discriminations. The positive discrimination is only concluded by an expert that has been trapped into the discriminative actions of an enterprise. This should be mentioned that all enterprises are not necessary to employ the disqualified individuals at any conditions in order to make a positive discrimination. Although the positive discrimination can construct many various opportunities for females and minorities but it can nurture and optimize this thinking that the effective management of the human force is an imperative case for the job place. For example, the positive discrimination is confronting with the tolerance of the white men potentially in compare to women because the positive discrimination is considered as a preference employment and a kind of behavior for them based on the group membership. Due to the mentioned statements, it seems that by increasing the lack of discrimination, the organizational growth will be also increased. The results represent that there is a positive significant relationship between the respect and the organizational growth of Erzurum physical education teachers that these are adapted with the results of Serhat et al (2015). He reported a positive significant relationship between the selfesteem (respect to the self) and the organizational growth. The diverse job force, talent and mental models can be brought to an organization and when these are conducted and oriented correctly, they will bring the knowledge-making, creation and innovation. Therefore, respecting to the individuals' differences is not merely established based on the moral and spiritual reasons but also they come from the economic advantage for the same organization. The results showed that there is a positive significant relationship between the cultural policies with the organizational growth in Erzurum City physical education teachers and this section of the study is adapted with the results of Gerol et al (2013). The positive point is that these problems are getting removed gradually over time while the cultural new groups can work together without having any problems together and these differences will be removed during three months. It can be also thought that the recent diversity of the groups except the entrance date of them entered into the group is an important case and the sexual differences, educational level and other factors are not be important cases for them; it can represent the obtained results that the physical education teachers constructing the cultural policies and using the diversity in their affairs can raise the organizational growth of Erzurum schools. Indeed it can be claimed that by 
increasing the construction of the cultural policies for valuing, the organizational growth will be also raised in this city. The results represent the positive relationship between the value for obtaining the better results and the organizational growth among physical education teachers of Erzurum City that these are similar to the results of Parker (2002), Gullu (2010) that they have also reported a positive relationship between the diversity management and the human force efficacy. Indeed by increasing the diversity management, the efficacy will be also increased; in other words, by increasing the valuing case for having better results, the organizational growth will be also increased among the physical education teachers of Erzurum City. The results represent that there is a positive significant relationship between the suitable proportion of the diversity and the organizational growth that these are adapted with the results of Gerol et al (2013) and Allen et al (2008) that they have reported a positive relationship between the diversity and the organizational performance. When confronting with every level of the job force diversity, the management should allocate some decisions in order to maximize the efficacy from this diversity for the same organization. For the reason, there should be established some useful strategies for employment and education affairs trying to grow all staffs; the praise system and the teamwork occupations design should be also allocated by the organizational management so that these issues should lead to the organizational growth and purposes regarding to Erzurum physical education teachers. Due to the above mentioned statements, by increasing the suitable proportion, the organizational growth will be also increased. The results represent that there is a positive relationship between the design of the policies for removing the discrimination and the organizational growth in Erzurum City physical education teachers. The results of the section are adapted with the results of Serhat et al (2015). When the positive discrimination programs are achieved successfully, the staffs will be also able to view these plans without any special support. The positive discrimination programs will have also negative effects such as the women and minorities will suffer from the expected benefits and scores. The studies have proofed that the women and minorities being employed as assumptive based on positive discrimination will not have better feeling towards their employment because they imagine that they are not considered as able people among other employers. They will also feel little job satisfaction having the highest stress and experiencing some comments all about themselves that they have been divided into some mechanisms as the diverse job force. Some management experts have suggested the positive discrimination plans for making and constructing the job force with the diversity process while other authors have criticized these kinds of programs. The positive discrimination polities are always provoking cases for the reason that the application of the preferences in the process of the employment should be confirmed and as a result it can be intertwined with one of the managerial features as the main meaning of selection based on ability and finally, the attraction of the best physical education teachers will be opposed in this regard. Due to the above mentioned statements, it seems that by increasing the design of removing policies of the discrimination, the organizational growth will be increased in Erzurum city physical education teachers.

\section{References}

Atali, F. (2009). Relationship of the diversity management of the job force and the organizational knowledge-making in higher education system; Journal of the Higher Education, 2(3), 115-134.

Firat, A. (2013). The role of management and policy-making of faculties and physical education groups in the conduction of the students' occupational expectations; Journal of the Applied Studies in Sport Management, 2(5), 121-138.

Goral, A. (2011). the diversity management skills and the cultural response to the minority and religious students' requirements; Journal of a New Approach Towards the Educational Management, 2(6), 131-154.

Gullu, M. (2010). the investigation of the relationship between the diversity management and human force efficacy, Journal of Management, 4, 72-89.

Power, M. (2008). A dual-mode university instructional design model for academic development. International Journal for Academic Development, 13(1), 31-39. https://doi.org/10.1080/13601440701860185

Robins, S. P. (2005). The organizational behavior: the concepts, theories and applications, Ankara, Ketab Publication.

Serhat, G. (2015). The role of diversity management and organizational growth of the scientific board members of all country's universities, Journal of Applied Studies in Sport Management, 2(10), 41-54.

\section{Copyrights}

Copyright for this article is retained by the author(s), with first publication rights granted to the journal.

This is an open-access article distributed under the terms and conditions of the Creative Commons Attribution license which permits unrestricted use, distribution, and reproduction in any medium, provided the original work is properly cited. 